\title{
Dose and Time Dependent Effect of N-Acetyl-L- Cysteine Supplementation on In Vitro Fertilization of Bovine Oocytes
}

\author{
Ngonput Agnes Elad ${ }^{1}$, Zelli Riccardo*1, Menchetti Laura ${ }^{1}$, Sylla Lakamy ${ }^{1}$, Stradaioli Giuseppe ${ }^{2}$, \\ Crociati Martina ${ }^{1}$ and Monaci Maurizio ${ }^{1}$ \\ ${ }^{1}$ Department of Veterinary Medicine, via S. Costanzo 4, 06126 Perugia, Italy \\ ${ }^{2}$ Department of Agricultural, Food, Environmental and Animal Sciences (DI4A), via DelleScienze 206, 33100, Udine, Italy \\ *Corresponding author: Riccardo Zelli, Department of Veterinary Medicine, via S. Costanzo 4, 06126 Perugia, Italy
}

\section{ARTICLE INFO}

Received: 幽 March 19, 2020

Published: May 07, 2020

Citation: Ngonput A E, Zelli R, Menchetti L, Sylla L,Stradaioli G, et al., Dose and Time Dependent Effect of N-Acetyl-L-Cysteine Supplementation on In Vitro Fertilization of Bovine Oocytes. Biomed J Sci \& Tech Res 27(3)-2020. BJSTR. MS.ID.004508.

Keywords: Semen; In Vitro Fertilization; Polyspermy; N-Acetyl-L-Cysteine; Bovine

Abbreviations: IVF: In vitroFertilization; ROS: Reactive Oxygen Species; NAC: $\mathrm{N}$-Acetyl-L-Cysteine; $\mathrm{H}_{2} \mathrm{O}_{2}$ : Hydrogen Peroxide; BSA: Bovine Serum Albumin; TCM: Tissue Culture Medium; COCs: Cumulus-Intact Oocyte Complexes

\section{SYNOPSIS}

In vitro fertilization (IVF) is a process that is exposed to high oxygen concentration $(20 \%)$ resulting in the production of reactive oxygen species (ROS). N-acetyl-Lcysteine (NAC) is a potent free radical scavenger. However, it is reported that NAC supplementation during IVF has no or detrimental effect on oocyte development. The present study was designed to evaluate the effects of different concentrations of NAC supplemented at different stages of in vitro culture of bovine oocytes on fertilization rate and polyspermy. In Experiment 1, NAC was added at a fixed concentration (1.25 $\mathrm{mM}$ ) to IVM medium (Group NAC IVM+/IVF-), to the fertilization medium (Group NAC IVM-/IVF+) and in both mediums (Group NAC IVM+/IVF+). In experiment 2, NAC was added only to the IVF medium at higher concentrations ( $5 \mathrm{mM}$ and $10 \mathrm{mM})$. The control group were processed without the addition of NAC in mediums.In the present work, NAC $(1.25 \mathrm{mM})$ negatively influenced the rate of fertilized oocytes only in a NAC IVM+/ IVF+ Group, while in Groups NAC IVM+/IVF- and IVM-/IVF+ a significant greater rate of normal fertilized oocytes has been recorded.In conclusion from the results of the present study we can state that addition of low doses of NAC $(1.25 \mathrm{mM})$ to the IVM or IVF medium has positive effects on the quality of the fertilized oocytes by reducing polyspermic rates, while doses greater than $5 \mathrm{mM}$ in IVF medium demonstrated a detrimental effect on the fertilization rate.

\section{Introduction}

In vitro fertilization of oocytes in general is a process that is exposed to high oxygen concentration $(20 \%)$ resulting in the production of reactive oxygen species (ROS) such as hydrogen peroxide $\left(\mathrm{H}_{2} \mathrm{O}_{2}\right)$, superoxide anion $\left(\mathrm{O}_{2}\right)$ and the hydroxyl radicals $(\mathrm{OH})[1,2]$. ROS are known to be involved in a wide range of physiological reproductive functions including sperm capacitation [3], oocyte maturation, steroidogenesis and corpus luteum function [4-6]. The negative effect of ROS on in vitro fertilized oocytes has been demonstrated in various animal species, due to induction of mitochondrial dysfunction [7], causing damage to nuclear material [8] as well as inhibiting oocyte-sperm fusion [9]. Oxidative stress

occurs when oxidants outnumber the antioxidants [10]; therefore, a balance between production of oxidants and their scavengers is an aspect of in vitro fertilization that can affect its outcome [11]. Moreover, both enzymatic and non-enzymatic antioxidants are involved in contrasting oxidative damage caused by ROS. Glutathione (GSH), a tripeptidethiol, is the main non-enzymatic antioxidant produced by gametes and helps in providing a reduced environment in IVF [12].

Glutathione synthesis is stimulated by the presence of other low molecular weight thiol compounds such as cysteine, cystine, cysteamine and $\beta$ mercaptoethanol, and reduced levels of GSH 
often lead to decreased numbers of competent oocytes during IVF $[12,13]$.N-acetyl-L-cysteine (NAC) is a potent free radical scavenger as a result of its nucleophilic actions on ROS and can be considered as a supplement to overcome GSH depletion and free radical formations during oxidative stress [14]. The molecular structure of NAC facilitates crossing of the plasma membrane where it is deacetylated; in this condition, thiol groups are available for glutathione synthesis within the gametes $[13,15,16]$. However, some research on bovine oocytes indicates that NAC supplementation during oocyte maturation has either no or a detrimental effect on oocyte development [12,17]. Recently, Rocha Frigoni, et al. [18] evaluated the effect of antioxidants during IVM both on oocytes quality and acquisition of developmental competence; they concluded that antioxidants improved oocytes quality but not increased embryo production rate.

The effect of supplementing NAC appears to be time and dose dependent; when supplemented in IVF systems during early stage of development, it reduces embryonic survival $[17,19]$, while an increase of foetal survival caused by reduction of oxidative stress was reported after oral administration in rat [20]. As regards the dose of NAC used in the IVF system there is a wide variability, ranging from 0.1-0.6 to 1,2 mM [17,21].Fertilization of the oocyte depends on the successful penetration by the sperm cell through the zona pellucida. Polyspermy is a process that involves penetration of the oocyte by more than one spermatic cell at fertilization [22]. Higher in vitro incidence of polyspermy compared to those in vivo has been reported $[23,24]$. Some studies attribute polyspermy to a lack of exposure of the freshly collected oocytes to the heparin oviductspecific glycoproteins complex that would help mask the fusion sites [22]. Other studies support the fact that reactions triggered by the release of the cortical granules contribute in blocking polyspermy [25-27].The present study was designed to evaluate the effects of different concentrations of NAC supplemented at different stages of in vitro culture of bovine oocytes on fertilization and polyspermy rate.

\section{Materials and Methods}

\section{Ethics Statement}

This study used ovaries obtained regularly from local bovine slaughterhouse, so no animal experiments were performed for the purpose of this study.

\section{Reagents and Media}

All reagents used were supplied by Sigma-Aldrich (Milan, Italy) unless otherwise specified.Medium for in vitro maturation (IVM) was tissue culture medium 199 (TCM199) (Gibco BRL, Grand Island, NY, USA) supplemented with $10 \%$ fetal calf serum (FCS; Gibco BRL), $0.2 \mathrm{mM}$ sodium pyruvate, $25 \mathrm{mM}$ sodium bicarbonate, $50 \mu \mathrm{g} / \mathrm{ml}$ amikacin, $0.5 \mu \mathrm{g} / \mathrm{ml}$ FSH (Pluset; HertapeCalier, Juatuba,
MG, Brazil), 100 IU/ml HCG (Profasi; Serono, Sao Paulo, Brazil) and $1.0 \mu \mathrm{g} / \mathrm{ml}$ estradiol-17- $\beta$. IVF medium consisted of Tyrode's albumin lactate pyruvate TALP [28], supplemented with $0.2 \mathrm{mM}$ Na-pyruvate, $6 \mathrm{mg} / \mathrm{ml}$ fatty acid-free bovine serum albumin (BSA), $25 \mathrm{mM}$ sodium bicarbonate, $13 \mathrm{mM}$ Na-lactate, $50 \mathrm{mg} / \mathrm{ml}$ amikacin, $4 \mu \mathrm{l} / \mathrm{ml}$ PHE solution ( $2 \mathrm{mM}$ penicillamine, $1 \mathrm{mM}$ hypotaurine, and $250 \mathrm{mM}$ epinephrine) and $10 \mathrm{mg} / \mathrm{ml}$ heparin.

\section{Oocyte Collection}

Bovine ovaries were obtained from regularly slaughtered beef cows, which were declared clinically healthy based on pre- and postmortem Veterinary Inspection and transported to the laboratory in sterile $\mathrm{NaCl}$ solution (9gr/L) supplemented with antibiotics (100mg/L streptomycin) at $23 / 25^{\circ} \mathrm{C}$ within 2 hours after slaughter. The ovaries were collected regardless of stage of the oestrous cycle of donors. Cumulus-intact oocyte complexes (COCs) were obtained by slicing ovaries and evaluated morphologically at a magnification $400 \times$ and classified as denuded, degenerated or healthy as reported by Vassena, et al. [29]. Only healthy COCs, with homogeneous oocyte cytoplasm and $>3$ layers of compact granulosa cells, were eligible for the experiment.

\section{In Vitro Maturation}

Pools of 30-35 oocytes each were incubated in four-well dishes, in $0.5 \mathrm{ml}$ of IVM medium at $38.5^{\circ} \mathrm{C}$ under an atmosphere of $5 \% \mathrm{CO}_{2}$ and $20 \% \mathrm{O}_{2}$ in humidified environment for 24 hours. After maturation, COCs were then decumulated in $2 \mathrm{ml}$ medium H-SOF supplemented with $20 \mu \mathrm{l}$ hyaluronidase through the mechanical action of the pipette leaving only the cellular layers of the corona radiata; complexes were then incubated until the time of fertilization.

\section{In Vitro Fertilization}

Frozen-thawed semen from Marchigiana bull with proven fertility was used. In order to obtain an adequate concentration of motile sperm for IVF, two doses were thawed, and semen was suspended on a Percoll gradient. In a $15 \mathrm{ml}$ falcon $2 \mathrm{ml}$ of $90 \%$ Percoll was deposited followed by $2 \mathrm{ml}$ of $45 \%$ Percoll and finally the sperm suspension was layered on. The tube was then centrifuged at $300 \mathrm{xg}$ for 40 minutes. Then pellet was collected and subsequently deposited in $2 \mathrm{ml}$ of TALP medium and centrifuged twice at $300 \mathrm{xg}$ for 10 minutes. Subsequently, sperm concentration was assessed through a haemocytometer; then the semen was resuspended in TALP-IVF medium in order to reach a final concentration of $2 \times 10^{6}$ sperm cells $/ \mathrm{ml}$ and left to incubate at $38^{\circ} \mathrm{C} 5 \% \mathrm{CO}_{2}$ in humidified environment for $60 \mathrm{~min}$. In each IVF well, 20 matured oocytes were co-incubated with $100 \mu \mathrm{l}$ of washed semen in an atmosphere of $5 \% \mathrm{CO}_{2}, 20 \% \mathrm{O}_{2}$ at $38.5^{\circ} \mathrm{C}$ in humidified environment.After 18 hours of incubation, zygotes were stripped from cumulus cells, then mounted on slides and fixed for 48 hours with $25 \%$ acetic 
acid at room temperature. After fixation, slides were stained with $1 \%$ orcein in $45 \%$ acetic acid. Zygotes were then examined using a phase-contrast microscope at 400X magnification and considered as non-fertilized if one pronucleus was observed, normally fertilized when two pronuclei were evident, and fertilized but polyspermic if more than two pronuclei were identified.

\section{Experimental Design}

In the experiment 1 NAC was added at a concentration of 1.25 $\mathrm{mM}$ as follows:

i) Oocytes matured in IVM medium supplemented with NAC and fertilized without supplementation of NAC in IVF medium (Group NAC IVM+/IVF-).

ii) Oocytes matured and fertilized with the supplementation of NAC in both mediums (Group NAC IVM+/IVF+).

iii) Oocytes supplemented with NAC only in the fertilization medium (Group NAC IVM-/IVF+).

iv) Oocytes matured and fertilized without supplementation of NAC on medium (Group NAC IVM-/IVF-).

In experiment 2, in order to evaluate the effects of a higher concentration, NAC was added at $5 \mathrm{mM}$ and $10 \mathrm{mM}$ to the IVF medium. The control group was processed without the addition of NAC in IVF medium.

\section{Statistical Analysis}

Statistical data in all experiments were analyzed using Chisquare test or Fisher's exact test and Bonferroni-adjusted Z-test. Statistical analysis was performed using SPSS statistics version 23 (IBM, SPSS Inc, Chicago, IL, USA) and P $<0.05$ was the accepted level of statistical significance.In both experiments, all the content within one well of a plate was defined as experimental unit while replicates were defined as the total number of wells analysed. Data were pooled from at list three replications.

\section{Results}

\section{Experiment 1: Effects of $1.25 \mathrm{mM}$ of NAC Supplemented in the IVM and/or IVF Mediums}

In the Group NAC IVM+/IVF+ there was a significant decrease in the rate of fertilized and consequent increase of unfertilized oocytes as compared to all other groups $(\chi=82.34 ; \mathrm{P}<0.001)$; (Figure 1 ).

The Groups of both NAC IVM+/IVF- and NAC IVM-/IVF+ showed higher normal fertilized and lower polyspermy compared to Group NAC IVM-/IVF- $(\chi=9.5 ; \mathrm{P}=0.023)$; (Table 1 ).

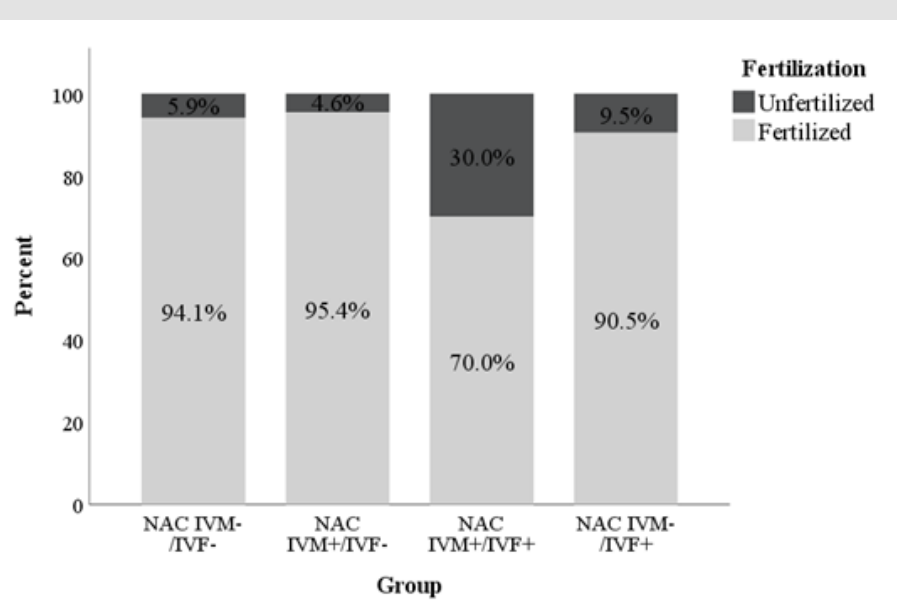

Figure 1: Effect of 1,25 mM of NAC supplemented in IVM and/or IVF medium on rates of fertilization (fertilized= normally fertilized and polyspermic. $\mathrm{P}<0.001)$.

Table 1: Effect of supplementation with $1.25 \mathrm{mM}$ of NAC in IVM and/or IVF medium on polyspermy.

\begin{tabular}{|c|c|c|c|c|}
\hline & \multicolumn{3}{|c|}{ Groups } \\
\hline Oocytes & NAC IVM-/IVF- & NAC IVM+/IVF- & NAC IVM+/IVF+ & NAC IVM-/IVF+ \\
\hline Fertilized & $106(83.5 \%)$ & $210(91.7 \%)^{*}$ & $145(86.3 \%)$ & $184(92.5 \%)^{*}$ \\
\hline Polyspermic & $21(16.5 \%)$ & $19(8.3 \%)^{*}$ & $23(13.7 \%)$ & $15(7.5 \%)^{*}$ \\
\hline Total & $127(100 \%)$ & $229(100 \%)$ & $168(100 \%)$ & $199(100 \%)$ \\
\hline
\end{tabular}

* Indicate statistically significant differences compared to the NAC -/- group at the 0.05 level. (Fertilized= normally fertilized) 


\section{Experiment 2: Effects of Supplementation to the IVF Medium of NAC at Higher Concentration}

When NAC was added at the concentration of $10 \mathrm{mM}$ in the IVF medium, a significant increase in the rate of unfertilized oocytes (39.9\%) was evident, when compared both to the control group
(6.4\%) and to $5 \mathrm{mM}$ group (9.4\%; $\chi=98.8 \mathrm{P}<0.001)$; (Figure 2).

Percentage of polyspermy was lower in $10 \mathrm{mM}$ NAC added group (5.6\%) compared to control (14.2\%), while 5mM NAC group showed intermediate rate $(9 \% ; \chi=6.9, \mathrm{P}=0.034)$; (Table 2$)$.

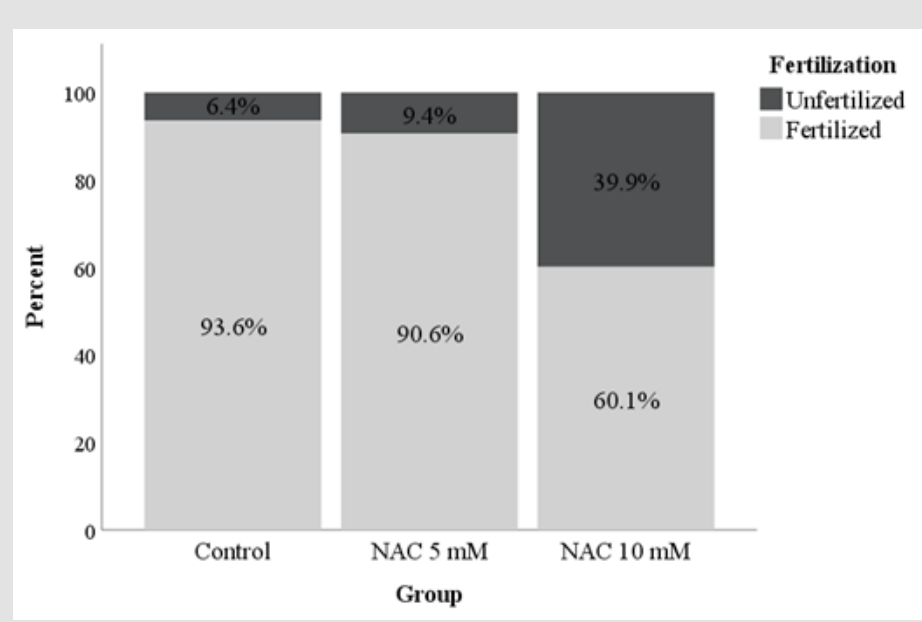

Figure 2: Effect of different concentrations of NAC ( $5 \mathrm{mM}$ and $10 \mathrm{mM})$ supplemented to IVF medium on the fertilization rate (fertilized $=$ normally fertilized and polyspermic. $\mathrm{P}<0.001)$.

Table 2: Effect of different concentrations of NAC (5mM and 10mM) supplemented in IVF medium on polyspermy.

\begin{tabular}{|c|c|c|c|}
\hline & \multicolumn{3}{|c|}{ Groups } \\
\hline Oocytes & Control & NAC 5 mM & NAC 10 mM \\
\hline Fertilized & $151(85.8 \%)$ & $193(91.0 \%)$ & $135(94.4 \%)^{*}$ \\
\hline Polyspermic & $25(14.2 \%)$ & $19(9.0 \%)$ & $8(5.6 \%)^{*}$ \\
\hline Total & $176(100 \%)$ & $212(100 \%)$ & $143(100 \%)$ \\
\hline
\end{tabular}

* Indicate statistically significant differences compared to the Control group at the 0.05 level. (Fertilized= normally fertilized)

\section{Discussion}

In the present study, the effects of $\mathrm{N}$-acetyl-cysteine added at fixed concentration at different stages of in vitro embryo production (experiment 1) or a different concentration in IVF medium were evaluated (experiment 2).

In the experiment 1, $1.25 \mathrm{mM}$ of NAC in the IVM and/or in the IVF medium were added in order to evaluate the time-dependent effects on two fundamental stages of in vitro embryo production. In the present work, NAC negatively influenced the rate of oocytes fertilization only when added simultaneously to IVM and IVF mediums. Lower fertilization rates seen in the Group NAC IVM+/IVF+ showed that supplementation of NAC in both mediums is harmful for the fertilization process. This could be due to the necessity of a certain quantity of free radicals for the coordination of specific physiological cell functions, including fertilization process [30,31].
It is also reported that ROS plays a role in the fertilizing capacity of bovine spermatozoa, as well as in the interaction between the spermatozoa and the oocytes [32] and hydrogen peroxide plays a crucial role in sperm capacitation[3,33,34].

The addition of NAC to both mediums could have reduced excessively the level of free radicals with consequent negative impact on fertilization.It is interesting to note that although there was no difference in fertilization rate between NAC IVM+/IVF- and NAC IVM-/IVF+ groups compared to control Group NAC IVM-/ IVF- (Figure 1), we observed that supplemented groups showed a significantly higher incidence of normally fertilized oocytes due to reduced polyspermy (Table 1 ). This is partially in accordance with results from Rocha Frigoni, et al. [18], that evaluated the effect of antioxidants during IVM and concluded that antioxidants improved the quality of oocytes but did not increase embryo production. 
Polyspermy is a condition characterized by penetration of the oocyte by more than one sperm cell at fertilization and under natural conditions its prevalence is moderate, while it remains a major obstacle to successful development of viable embryos in IVF systems [24]. A block of polyspermy develops as a result of cellular changes after first sperm penetration (i.e. cortical granule exocytosis)[22].

The proposed mechanisms that influence this phenomenon have been attributed to the hardening of the zona pellucida by the protein ovastacin that cleaves ZP2 preventing sperm binding [35], or a membrane depolarization after spermatozoa fusion caused by a release of spermatozoa phospholipase $\mathrm{C}$ and consequent increase in chloride permeability due to the opening of IP3-gate calcium-channel in the endoplasmatic reticulum [36]. The oocyte maturation associated with the remodeling and distribution of calcium ion channels is fundamental for proper fertilization [37]. Another mechanism reported in the cow and pig considers the plasminogen/plasmin system as sperm removal factors from the surface of the egg cell by detaching more than $50 \%$ of sperm bound to the ZP [38]. Recently, it has been identified the receptor on the oocyte (Juno) complementary to that of the spermatozoon (izumo 1), as essential for fertilization. Female mice lacking Juno are infertile and Juno-deficient eggs do not fuse with normal sperm. Rapid shedding of Juno from the oolemma after fertilization suggests a mechanism for the membrane block to polyspermy, ensuring eggs normally fuse with just a single sperm $[39,40]$.

The significant reduction of polyspermy in our first experiment could be caused by the positive effect of NAC in maturational process of the oocytes (Group NAC IVM+/IVF-) or at the level of spermatozoa decreasing sperm capacity to penetrate the oocytes (Group NAC IVM-/IVF+). In fact, supplementation with antioxidant during IVF procedures compromises sperm quality [32].In the second experiment we added NAC only in the IVF medium to evaluate the effect of higher concentrations of this antioxidant on fertilization process. We noticed a lower fertilization rate in $10 \mathrm{mM}$ group compared to the control and $5 \mathrm{mM}$ group, and this allowed us to state that at the highest concentrations, NAC has a negative effect on fertilization process. However, at greater concentrations of NAC, the percentage of normally fertilized oocytes as in the first experiment was significantly higher than the control and the $5 \mathrm{mM}$ group, due to a decreased polyspermic rate.

\section{Conclusion}

In conclusion from the results of the present study we can state that addition of low doses of NAC (1.25 mM) to the IVM or IVF medium has positive effects on the quality of the fertilized oocytes by reducing polyspermic rates, while doses greater than $5 \mathrm{mM}$ in IVF medium demonstrated a detrimental effect on the fertilization rate. However, further studies are necessary to determine the more suitable concentration of antioxidant to be used at different moment during IVF of bovine oocytes and the effects of this or other substrates in later stages of embryonic development.

\section{Acknowledgement}

The research and laboratory material purchase were supported by a Public grant from University of Perugia (Italy).

\section{Declaration of Interest}

The authors declare that there is no conflict of interest that could be perceived as prejudicing the impartiality of the research reported.

\section{Data Availability Statement}

The data that support the findings of this study are available from the corresponding author upon reasonable request.

\section{References}

1. Luvoni GC, Keskintepe L, Brackett BG (1996) Improvement in bovine embryo production in vitro by glutathione-containing culture media. Molecular Reproduction Development 43(4): 437-443.

2. Guérin P, El Mouatassim S, Ménézo Y (2001) Oxidative stress and protection against reactive oxygen species in the pre-implantation embryo and its surroundings. Human Reproduction Update 7(2): 175189.

3. Bize I, Santander G, Cabello P, Driscoll D, Sharpe C (1991) Hydrogen peroxide is involved in hamster sperm capacitation in vitro. Biology of Reproduction 44(3): 398-403.

4. Ishikawa M (1993) Oxygen radicals-superoxide dismutase system and reproduction medicine. Nihon SankaFujinka Gakkai Zasshi 45(8): 842848.

5. Sabatini L, Wilson C, Lower A, Al Shawaf T, Grudzinskas JG (1999) Superoxide dismutase activity in human follicular fluid after controlled ovarian hyperstimulation in women undergoing in vitro fertilization. Fertility and Sterility 72(6): 1027-1034.

6. Behrman HR, Kodaman PH, Preston SL, Gao S (2001) Oxidative stress and the ovary. Journal of the Society for Gynecologic Investigation 8: S40-42.

7. Halliwell B, Aruoma OI (1991) DNA damage by oxygen-derived species. Its mechanism and measurement in mammalian systems. Federation of European Biochemical Societies Letters 281(1-2): 9-19.

8. Liu J, Liu M, Ye X, Liu K, Huang J, et al. (2012) Delay in oocyte aging in mice by the antioxidant $\mathrm{N}$-acetyl-L-cysteine (NAC). Human Reproduction 27(5): 1411-1420.

9. Aitken RJ, Harkiss D, Buckingham D (1993) Relationship between ironCatalysed lipid peroxidation potential and human sperm function. Journal of Reproduction and Fertility 98(1): 257-265.

10. Sies H (1991) Oxidative stress: from basic research to clinical application. American Journal of Medicine 91(3C): 31S-38S.

11. de Lamirande E, Jiang H, Zini A, Kodama H, Gagnon C (1997) Reactive oxygen species and sperm physiology. Rev Reproduction 2(1): 48-54.

12. de Matos DG, Furnus CC (2000) The importance of having high glutathione (GSH) level after bovine in vitro maturation on embryo development effect of beta-mercaptoethanol, cysteine and cystine. Theriogenology 53(3): 761-771. 
13. de Matos DG, Furnus CC, Moses DF (1997) Glutathione synthesis during in vitro maturation of bovine oocytes: role of cumulus cells. Biology of Reproduction 57(6): 1420-1425.

14. de Matos DG, Furnus CC, Moses DF (1997) Glutathione synthesis during in vitro maturation of bovine oocytes: role of cumulus cells. Biology of Reproduction 57(6): 1420-1425.

15. Keskes Ammar L, FekiChakroun N, Rebai T, Sahnoun Z, Ghozzi H, et al. (2003) Sperm oxidative stress and the effect of an oral vitamin E and selenium supplement on semen quality in infertile men. Archive of Andrology 49(2): 83-94.

16. Safarinejad MR, Safarinejad S (2009) Efficacy of selenium and/or $\mathrm{N}$-acetyl-cysteine for improving semen parameters in infertile men: a double-blind, placebo controlled, randomized study. Journal of Urology 181(2): 741-751

17. Ali AA, Bilodeau JF, Sirard MA (2003) Antioxidant requirements for bovine oocytes varies during in vitro maturation, fertilization and development. Theriogenology 59(3-4): 939-949.

18. Rocha Frigoni NA, Leão BC, Dall'Acqua PC, Mingoti GZ (2016) Improving the cytoplasmic maturation of bovine oocytes matured in vitro with intracellular and/or extracellular antioxidants is not associated with increased rates of embryo development. Theriogenology 86(8): 18971905.

19. Nishikimi A, Mukai J, Yamada M (1999) Nuclear translocation of nuclear factor kappa B in early 1-cell mouse embryos. Biology of Reproduction 60(6): 1536-1541.

20. Xu DX, Chen YH, Wang H, Zhao L, Wang JP, et al. (2005) Effect of $\mathrm{N}$-acetylcysteine on lipopolysaccharide-induced intra-uterine fetal death and intra-uterine growth retardation in mice. Toxicology Science 88(2): 525-533.

21. Takeo S, Kawahara Miki R, Goto H, Cao F, Kimura K, et al. (2013) Ageassociated changes in gene expression and developmental competence of bovine oocytes, and a possible countermeasure against age-associated events. Molecular Reproduction Development 80(7): 508-521.

22. Coy P, Cánovas S, Mondéjar I, Saavedra MD, Romar R, et al. (2008) Oviduct-specific glycoprotein and heparin modulate sperm-zona pellucida interaction during fertilization and contribute to the control of polyspermy. Proceding National Academic Sciences 105(41): 1580915814.

23. Leibfried Rutledge ML, Critser ES, Eyestone WH, Northey DL, First NL (1987) Development potential of bovine oocytes matured in vitro or in vivo. Biology of Reproduction 36(2): 376-383.

24. Aoki VW, Peterson CM, Parker Jones K, Hatasaka HH, Gibson M, et al. (2005) Correlation of sperm penetration assay score with polyspermy rate in in-vitro fertilization. Journal of Experimental Clinical Assisted Reproduction 2: 3 .

25. Dandekar P, Talbot P (1992) Perivitelline space of mammalian oocytes: extracellular matrix of unfertilized oocytes and formation of a cortical granule envelope following fertilization. Molecular Reproduction Development 31(2): 135-143.

ISSN: 2574-1241

DOI: $10.26717 /$ BJSTR.2020.27.004508

\section{Riccardo Zelli. Biomed J Sci \& Tech Res}

This work is licensed under Creative

Commons Attribution 4.0 License

Submission Link: https://biomedres.us/submit-manuscript.php
26. Hoodbhoy T, Talbot P (1994) Mammalian cortical granules: contents, fate, and function. Molecular Reproduction \& Development 39(4): 439448.

27. Papi M, Brunelli R, Sylla L, Parasassi T, Monaci M, et al. (2010) Mechanical properties of zona pellucida hardening. European Biophysiology Journal 39(6): 987-992.

28. Parrish JJ, Susko Parrish J, Winer MA, First NL (1988) Capacitation of bovine sperm by heparin. Biology of Reproduction 38(5): 1171-1180.

29. Vassena R, Mapletoft RJ, Allodi S, Singh J, Adams GP (2003) Morphology and developmental competence of bovine oocytes relative to follicular status. Theriogenology 60(5): 923-932.

30. Blondin P, Coenen K, Sirard MA (1997) The impact of reactive oxygen species on bovine sperm fertilizing ability and oocyte maturation. Journal of Andrology 18(4): 454-460.

31.Zhang J, Wang X, Vikash V, Ye Q, Wu D, et al. (2016) ROS and ROSMediated Cellular Signaling. Oxidative Medicine and Cellular Longevity 2016: 4350965

32. Gonçalves FS, Barretto LS, Arruda RP, Perri SH, Mingoti GZ (2010) Effect of antioxidants during bovine in vitro fertilization procedures on spermatozoa and embryo development. Reproduction in Domestic Animals 45(1): 129-135.

33. Griveau JF, Renard P, Le Lannou D (1994) An in vitro promoting role for hydrogen peroxide in human sperm capacitation. International Journal of Andrology 17(6): 300-307.

34. Aitken RJ, Buckingham DW, Harkiss D, Paterson M, Fisher H, et al. (1996) The extragenomic action of progesterone on human spermatozoa is influenced by redox regulated changes in tyrosine phosphorylation during capacitation. Mol Cell Endocrinol 117(1): 83-93.

35. Burkart AD, Xiong B, Baibakov B, Jiménez Movilla M, Dean J (2012) Ovastacin, a cortical granule protease, cleaves ZP2 in the zona pellucida to prevent polyspermy. Journal Cell Biology 197(1): 37-44.

36. Jaffe LA (2018) The fast block to polyspermy: New insight into a centuryold problem. Journal Genetic Physiology 150(9): 1233-1234.

37. Carvacho I, Piesche M, Maier TJ, Machaca K (2018) Ion Channel Function During Oocyte Maturation and Fertilization. Frontiers in Cell and Developmental Biology 6: 63

38. Grullón LA, Gadea J, Mondéjar I, Matás C, Romar R, et al. (2013) How is plasminogen/plasmin system contributing to regulate sperm entry into the oocyte? Reproductive Sciences 20(9): 1075-1082.

39. Bianchi E, Doe B, Goulding D, Wright GJ (2014) Juno is the egg Izumo receptor and is essential for mammalian fertilization. Nature 508(7497): 483-487.

40. Vajta G, Rindom N, Peura TT, Holm P, Greve T, et al. (1999) The effect of media, serum and temperature on in vitro survival of bovine blastocysts after Open Pulled Straw (OPS) vitrification. Theriogenology 52(5): 939498

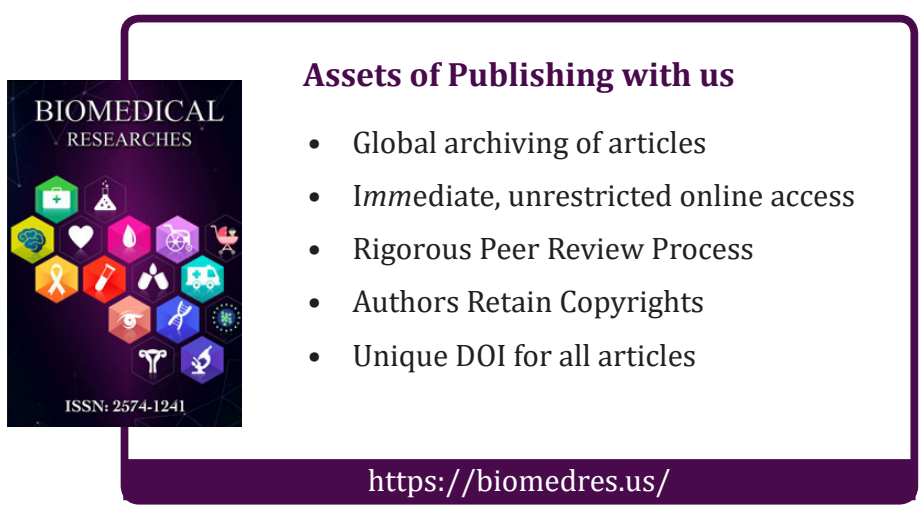

